\title{
Application of CAD Technology in Building Decoration Construction
}

\author{
Yingying Shao* \\ Zibo Vocational Institute, Zibo 255314, Shandong Province, China
}

*Corresponding author: Yingying Shao, tomohisa0920@sina.cn

\begin{abstract}
With the rapid development of science and technology, the application scope of computer technology and related software is expanding, while improving the work efficiency of various industries, the quality of people's work has also been greatly improved. In particular, as an important part of China's economic development, the construction industry has gradually applied some new technical means, and achieved remarkable application results. CAD technology drawing can not only improve the standardization of scheme design, but also effectively shorten the time, which is of great significance to the improvement of construction quality. This paper focuses on the application of computer technology (CAD) in the construction of building decoration, and hopes to provide reference and suggestions for relevant personnel.
\end{abstract}

Keywords: CAD technology; Architectural ornament; Decorate; Computer technology

Publication date: September 2021; Online publication: September 30, 2021

\section{Introduction}

liberate from the drawing board, greatly improves the work efficiency, but due to the architectural decoration project construction has a certain practicality and complexity, there is a gap between the actual situation of the construction site and the planning. CAD technology application scope in the practical engineering construction is limited, which results in a great difference between the practical effect and the design planning. Therefore, in order to ensure the quality of the project, it is necessary to carry out secondary CAD design according to the construction site. With the development of computer technology, the application of information technology in engineering construction management has become an inevitable trend of the development of project management. The application of CAD technology in the field of construction industry plays an important role in improving the quality and efficiency of construction.

\section{Necessity of the application of CAD technology in building decoration construction}

CAD technology is a kind of application software based on computer, which can help designers to complete the design work. It can not only complete the 2D construction drawing, but also give consideration to the generation of 3D models. For the construction of architectural decoration engineering, it has a good guiding role. In 2D drawing, the drawing is generally regarded as a collection of basic graphics such as points, lines, circles, rectangles and arcs. The application of 3D technology can be closer to the performance of the actual shape. Their combined use can fully express the design information and make the drawing expression more perfect and accurate. Moreover, CAD technology has a powerful storage function, which can store multiple drawings in one system environment at the same time. For example, when drawing the floor tile pavement drawing, the effect reaction after construction can be truly presented through CAD technology, the brick cutting position and brick laying method can be defined, and the required bricks can be accurately calculated to reduce the loss of materials. The application of CAD technology in architectural decoration design can 
connect art with architectural entities and increase the artistic and cultural value of design. For another example, when we are facing a large-scale building structure, designers cannot master the brightness of light according to the building area. At this time, we can apply CAD technology to accurately adjust the brightness and sound insulation effect of interior light, and integrate the application of CAD technology into artistic beauty, which can greatly enhance the quality of design projects ${ }^{[1]}$.

At present, the construction process of building decoration engineering in China is still based on the drawing as the main reference. In the actual construction process, the construction personnel are lack of strain capacity and cannot compare the drawings with the actual situation of the construction site. They make less research and analysis on the drawings, and basically will not be optimized again. Over time, this construction method has a certain obstacle to the development of the construction industry. First, even if the project is successfully completed and the structural design is consistent with the drawings, the space utilization rate is not high and some decoration quality is far-fetched. Second, there are big differences between the project after completion and the drawing design. Such problems are mainly caused by designers' lack of practice, the designers failed to walk into the construction site for practical investigation, only relied on their own design experience with data to carry out project design, which brings hidden trouble to the construction work. Some units will cause a flaw in some area due to meet construction drawing design blindly ${ }^{[2]}$. Therefore, it is necessary to use CAD technology to carry out secondary design with drawings as reference, and integrate all the data generated in the design, so as to ensure the proper placement of pipelines and equipment and reduce the construction difficulty.

\section{Specific application of CAD technology in building decoration construction 3.1.Application of CAD technology in construction guidance}

From Figure 1., we can see that CAD technology is widely used in the construction of Building Decoration Engineering, involving all aspects of decoration management, mainly including construction progress control, material control, construction quality control, adjustment of professionals, etc. Open the electronic construction design drawing with CAD, redefine the layers of each section of the design drawing, and then summarize the latest chart scheme according to the experience of several large decoration projects, to provide reference for the construction. Applying CAD technology to parametric design can effectively improve the professionalism and accuracy of drawings.

In the building decoration engineering, hydropower engineering is closely related to the drawing design, and hydropower engineering is an implicit project in the construction project. The drawing method of the system drawing is also draw in schematic way, which will only simply mark its approximate position. In the specific construction process, there are too many variable factors, which often leads to the failure of the staff on the construction site to accurately construct according to the drawing ${ }^{[3]}$. There are differences between actual construction and drawing design. At this time, it is necessary to use CAD technology to carry out secondary design on the actual situation of the construction site to solve the contradiction between them.

The design requirements of modern and intelligent large-scale buildings are higher and higher, and the scope of decoration industry is wider and wider, involving a variety of process means such as water, electricity, heating, glass, paint and metal. After these processes are completed, the processes of fire protection, sound, communication, network and other projects should be considered, so that the work can be completed smoothly in shifts. For example, if one cabinet has been installed, but the other cannot be completed on time due to problems in reserved space, the solution can only be to adjust the size of one or both sides to meet the completion of the target work, which will not only affect the construction period, but also bring losses to economic benefits. If CAD technology can be used to accurately locate each construction project before construction, the above problems can be effectively solved and work efficiency 
can be improved.

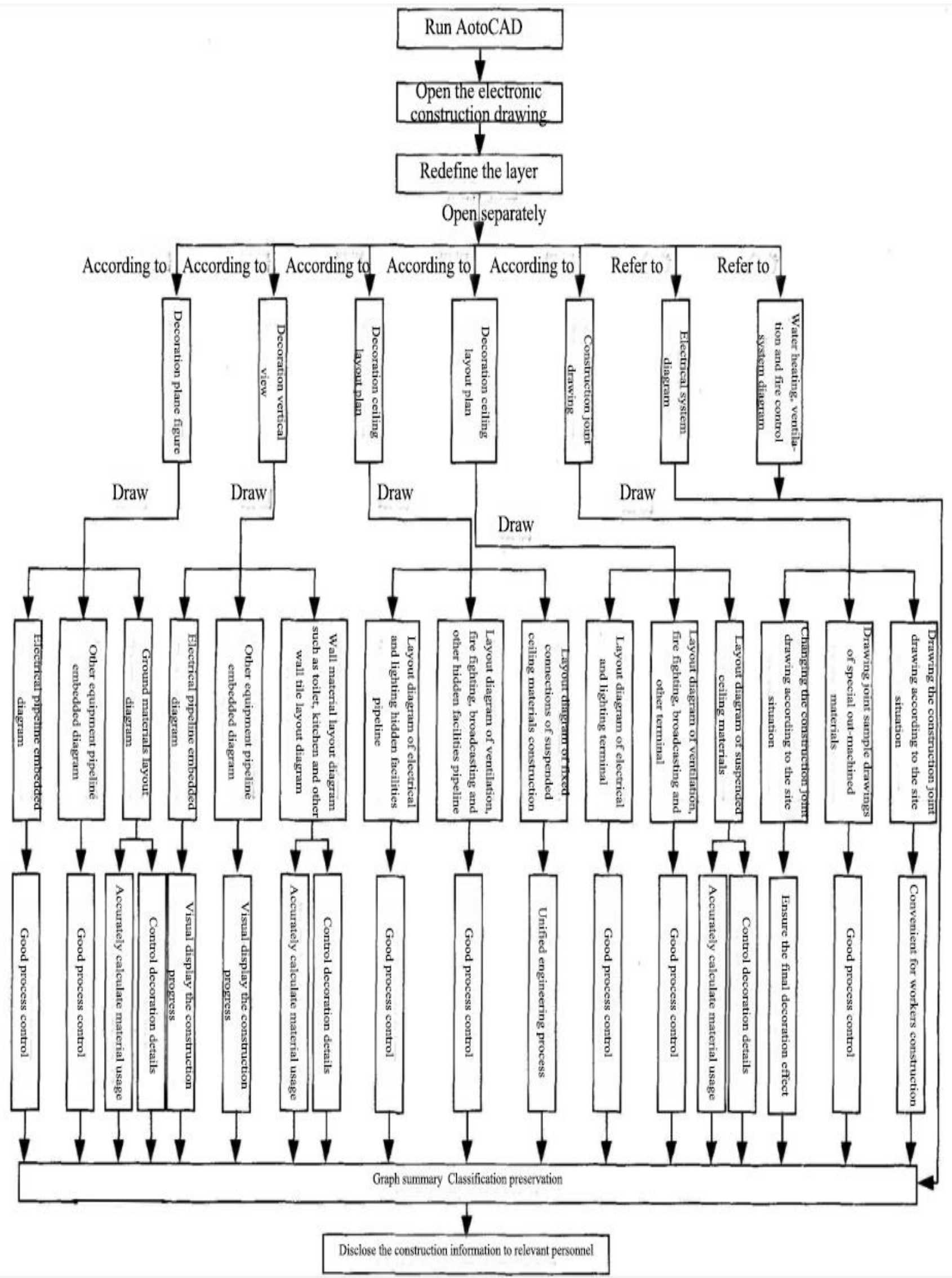

Figure 1. Framework of application program of CAD technology in building decoration construction 


\subsection{The significance of secondary design using CAD technology}

Generally, the construction drawings only include the basic house type design and material marking. The construction details and node marking are not clear, especially in the construction of reconstruction project, the drawings are often inconsistent with the on-site dimensions. At this time, on-site engineering and technical personnel are required to improve and change the design drawings and draw accurate construction drawings by using CAD technology, so as to ensure the smooth progress of the project.

CAD technology is used to assist the secondary design of construction drawings. Firstly, computer technology is used to facilitate the work, greatly reduce the workload of the staff on the construction site, strictly control the project quality, and show the progress of construction period and material supply more clearly. Secondly, create a good cooperation platform for secondary development, promote all participants of the project to work together, and greatly improve the construction quality and efficiency of building decoration engineering.

Therefore, from the construction situation of the construction industry, on-site engineering and technical personnel should reasonably use CAD technology means to quickly complete the construction scheme, and do a good job in the guidance and coordination of the construction scheme, so as to realize the large-scale, systematic and standardized construction management mode, which can make managers use it as a reference basis to complete the work tasks, and then obtain greater social benefits.

\section{Conclusion}

In conclusion, the development and application of CAD technology has brought great changes to the architectural decoration industry, and the traditional paper drawing design has been unable to meet the needs of the development of modern science and technology. It is necessary to carry on the secondary design and development, so as to ensure the smooth construction project. CAD technology is redesigned and integrated according to the on-site design drawings, accurately grasp the on-site construction situation, and formulate a more detailed feasibility scheme according to the specific marking contents of the drawings, so as to effectively avoid unnecessary losses and enhance the core competitiveness of the enterprise in the market.

\section{Disclosure statement}

The author declares no conflict of interest.

\section{References}

[1] Huang YQ, 2019, Discussion on Application of CAD Technology in Building Decoration Construction. Real Estate Guide, (2): 118.

[2] Xue S, 2021, Evaluation and Analysis of Application of CAD Technology Drawing in Building Decoration Construction. Architecture and Decoration, (16): 160.

[3] Ji LJ, 2020, Practice and Exploration on Introducing Architectural Engineering Drawing into CAD Teaching. Construction Materials \& Decoration, (4): 189-190.

[4] Kong YL, 2020, Preliminary Study on Integrating BIM Technology into Building Decoration Engineering. Journal of Huanghe S\&T College, 22(8): 46-49. 